\title{
TRIBUNAL CONSTITUCIONAL Y DERECHOS DE LOS EXTRANJEROS. COMENTARIO A LA RECIENTE JURISPRUDENCIA EN MATERIA DE EXTRANJERÍA
}

\author{
JUAN MANUEL GOIG MARTÍNEZ \\ Profesor Titular de Derecho Constitucional \\ UNED
}

\begin{abstract}
SUMARIO
I. El enjuiciamiento constitucional de la LO $4 / 2000$, en su versión dada por LO $8 / 2000$.

II. La importancia de los fallos, y sus consecuencias.
\end{abstract}

\section{EL ENJUICIAMIENTO CONSTITUCIONAL DE LA L.O 4/2000, EN SU VERSIÓN DADA POR L.O 8/2000}

\section{i.1. Presupuesto impugnatorio}

En el recurso de inconstitucionalidad núm. 1707-2001, interpuesto por el Parlamento de Navarra, contra diversos preceptos de la Ley Orgánica 8/2000, de 22 de diciembre, de reforma de la Ley Orgánica 4/2000, de 11 de enero, sobre Derechos y Libertades de los Extranjeros en España y su Integración Social, de siete de noviembre, el TC resuelve, por primera vez la posible inconstitucionalidad de una ley que niega el ejercicio de determinados derechos no a los extranjeros en general, sino a aquéllos que no dispongan de la correspondiente autorización de estancia o residencia en España, y en ella procede a hacer una nueva interpretación de las potestades del legislador, en virtud del contenido del art. 13.1 CE, a la hora de regular el ámbito de derechos y libertades de los derechos de los extranjeros.

Bajo dos premisas previas se plantea el TC en la STC 236/2007, de 7 de noviembre el enjuiciamiento de los preceptos de la L.O 8/2000 impugnados en 
el recurso, al objeto de dar respuesta a los concretos normativos de inconstitucionalidad alegados por la entidad recurrente frente a cada uno de ellos:

1. El juicio de constitucionalidad que debe realizar en el presente proceso no consiste en examinar si en el marco constitucional cabrían otras opciones en materia de extranjería distintas a la adoptada por la Ley Orgánica 8/2000, de 22 de diciembre, sino en determinar si los preceptos de esa Ley sometidos a su enjuiciamiento han excedido o no los límites impuestos por la Constitución.

2. Al enjuiciar la Ley impugnada en este proceso, corresponde determinar si el legislador ha respetado los límites impuestos ex art. 10.2 CE por las normas internacionales, que le obligan a interpretar de acuerdo con ellas los derechos y libertades consagrados en nuestra Constitución. Las normas legales impugnadas deben ser contrastadas con los correspondientes preceptos constitucionales que proclaman los derechos y libertades de los extranjeros en España, interpretados de acuerdo con el contenido de dichos Tratados o Convenios. En consecuencia, sólo podrá declararse su inconstitucionalidad si aquellas normas con rango de ley vulneran el contenido constitucionalmente declarado de tales derechos y libertades.

Estos criterios fundamentales reconocidos por el TC en la STC 236/2007, de 7 de noviembre, han sido ratificados por el resto de Sentencias dictadas por el TC a la hora de enjuiciar la constitucionalidad de la L.O 4/2000, en su versión dada por la L.O 8/2000: STC 259/2007, de 19 de diciembre de 2007; STC 260/2007, de 20 de diciembre de 2007; STC 261/2007, de 20 de diciembre de 2007; STC 262/2007, de 20 de diciembre de 2007; STC 263/2007, de 20 de diciembre de 2007; STC 264/2007, de 20 de diciembre de 2007, y STC 265/2007, de 20 de diciembre de 2007.

I.2. LA LEY 8/2000 SOBRE DERECHOS Y LIBERTADES DE LOS EXTRANJEROS Y SU INTEGRACIÓN SOCIAL, Y LAS LIMITACIONES A DERECHOS Y LIBERTADES. EL CRITERIO DEL TRIBUNAL CONSTITUCIONAL

La L.O 4/2000, de 11 de enero, sobre Derechos y Libertades de los inmigrantes y su integración social, constituyó un intento de equiparar a inmigrantes y españoles no sólo en derechos fundamentales, sino también en los llamados "derechos económicos, sociales y culturales" sin distinguir, salvo para aquellos para los que se exija, al igual que para los españoles, el cumplimiento de determinados requisitos, en virtud de la situación administrativa, favoreciendo la integración social y luchando contra la discriminación, sin embargo su vida fue efímera. Su reforma por L.O 8/2000, de 22 de diciembre, afecta a gran parte del articulado, crea nuevos preceptos y nuevas Disposiciones y, principalmente, viene a modificar el espíritu y la intención con que 
fue aprobada la L.O 4/2000, lo que nos lleva a afirmar que el resultado de esta reforma, es una Nueva Ley de Extranjería.

Tras la reforma, que afecta a un $80 \%$ de la Ley, no sólo se modifica gran parte del sistema de entrada, salida, permanencia y situaciones de los inmigrantes, sino que se cambia el reconocimiento de derechos a los extranjeros, retornando a una situación muy parecida a la contemplada por la L.O 7/1985, al recuperar la clara distinción entre los extranjeros dependiendo de su situación administrativa.

A través de los distintos recursos de inconstitucionalidad planteados, se recurre la inconstitucionalidad de los preceptos de la L.O. 8/2000, que dan nueva redacción a los artículos de la L.O. 4/2000 que regulan el derecho de reunión y manifestación (art. 7); el derecho de asociación (art. 8); el derecho a la educación (art. 9.3); el derecho de sindicación (art. 11.1); el derecho a la huelga (art. 11.2); el derecho a la tutela judicial efectiva (art. 22.2) y otros preceptos de la ley, por considerar que vulneran los artículos 17; 18; 19; 21; 22; 24; 25; 27 y 29 de la Constitución en su interpretación por los Tratados y Convenios Internacionales sobre la materia ratificados por España.

\section{I.2.1. El derecho de reunión y manifestación.}

El primer precepto recurrido es el contenido en el punto 5 del artículo primero, que da una nueva redacción al apartado 1 del art. 7 de la Ley Orgánica 4/2000, según el cual:

"Los extranjeros tendrán el derecho de reunión y manifestación, conforme a las leyes que lo regulan para los españoles y que podrán ejercer cuando obtengan autorización de estancia o residencia en Españan.

Los recurrentes sostienen que el precepto es contrario al art. $21 \mathrm{CE}$ en conexión con la Declaración Universal de los Derechos Humanos, el Pacto Internacional de Derechos Civiles y Políticos, y los arts. 9, 11 y 14 del Convenio Europeo para la Protección de los Derechos Humanos y Libertades Fundamentales (CEDH). Y ello porque siendo un derecho derivado de la dignidad humana, se establece una distinción en su ejercicio entre españoles y extranjeros que carece de cobertura constitucional, limitando su ejercicio efectivo a quienes estén legalmente en España.

La STC 284/2005, recogiendo anteriores pronunciamientos del Tribunal (especialmente las SSTC 195/2003; 196/2002; 66/1995), ha sintetizado el contenido y significado del derecho fundamental de reunión (art. $21 \mathrm{CE}$ ). El derecho de reunión, es una manifestación colectiva de la libertad de expresión ejercitada a través de una asociación transitoria de personas, que opera a modo de técnica instrumental puesta al servicio del intercambio o exposición de ideas, la defensa de intereses o la publicidad de problemas y reivindicaciones, y cuyos elementos configuradores son el subjetivo ,agrupación de personas, el temporal, duración transitoria, el finalista, licitud de la finalidad, y el real y objetivo, lugar de celebración (por todas, STC 85/1988), habiendo des- 
tacado en múltiples Sentencias el relieve fundamental que este derecho — cauce del principio democrático participativo- posee, tanto en su dimensión subjetiva como en la objetiva, en un Estado social y democrático de Derecho como el proclamado en la Constitución. Para muchos grupos sociales este derecho es, en la práctica, uno de los pocos medios de los que disponen para poder expresar públicamente sus ideas y reivindicaciones. ${ }^{1}$

Se trata de derechos que son manifestación del pluralismo político y de la libertad, proclamados como valores superiores, que se convierten en técnicas instrumentales puestas al servicio de un intercambio de ideas, la defensa de unos intereses o la publicidad de problemas o reivindicaciones. Son derechos individuales de libertad, de libertad personal con una clara proyección social y apoyo social para su realización ${ }^{2}$. Y son, también, derechos que cumplen una función estructural importante en la realización del Estado social y democrático de Derecho. Estos derechos se constituyen, por tanto, en derechos esenciales de cualquier sociedad democrática por cuanto fortalecen las estructuras democráticas de la sociedad, lo que revierte en el fortalecimiento de todas las instituciones democráticas y contribuyen a la presencia de la diversidad cultural.

El propio TC, sin vincular, en sus primeros pronunciamientos, estos derechos directamente a la dignidad humana, ha declarado expresamente que los extranjeros son titulares de los derechos de asociación, reunión y manifestación (STC 115/1987), al establecer que el art. 21 afirma genéricamente que se reconoce el derecho de reunión pacífica y sin armas "sin ninguna referencia a la nacionalidad del que ejerce este derecho, a diferencia de otros artículos contenidos en el Título I, donde se menciona expresamente a los españoles, y a diferencia también de otras Constituciones comparadas donde expresamente este derecho se reserva a los ciudadanos", y que "debe admitirse que, de acuerdo a sus propios términos, el art. 22 de la Constitución, en contraste con otras Constituciones comparadas, reconoce también directamente a los extranjeros el derecho de asociación".

Como indica el TC, el precepto enjuiciado establece una equiparación entre españoles y extranjeros en cuanto a la titularidad y el ejercicio del derecho de reunión, exigiendo sin embargo un requisito para los segundos, a saber, que éstos hayan obtenido la autorización de estancia o residencia en España. Podría entenderse pues que se trata de uno de los "condicionamientos adicionales" que, como se ha dicho, el legislador puede legítimamente establecer

1 La vinculación libertad de expresión-libertad de reunión ha sido igualmente destacada por el Tribunal Europeo de Derechos Humanos en muchas de sus Sentencias, señalando a este respecto que "la protección de las opiniones y de la libertad de expresarlas constituye uno de los objetivos de la libertad de reunión" (STEDH caso Stankov, de 13 de febrero de 2003, \ 85), y afirmando que "la libertad de expresión constituye uno de los medios principales que permite asegurar el disfrute efectivo del derecho a la libertad de reunión y de asociación" (STEDH caso Rekvényi, de 20 de mayo de 1999, \58).”. En el mismo sentido se ha pronunciado la STC 163/2006.

2 Soriano Díaz, R.- "El art. 21. Derecho de reunión" en Alzaga Villaamil, O (Dir)Comentarios a la Constitución española de 1978, T.II, 1997, Op. cit, pág. 578. 
al ejercicio de un derecho que «la Constitución reconoce directamente a los extranjeros". Pero el precepto debatido no se limita a condicionar el ejercicio del derecho de reunión por parte de los extranjeros en situación irregular sino que impide radicalmente cualquier ejercicio del mismo a las personas que se encuentren en España en aquella situación."

La definición constitucional del derecho de reunión realizada por nuestra jurisprudencia constitucional, y su vinculación con la dignidad de la persona, derivada de los textos internacionales, imponen al legislador el reconocimiento de un contenido mínimo de aquel derecho a la persona en cuanto tal, cualquiera que sea la situación en que se encuentre. El TC ha declarado que "el ejercicio del derecho de reunión y de manifestación forma parte de aquellos derechos que, según el art. $10 \mathrm{CE}$, son el fundamento del orden político y de la paz social', por lo que 'el principio de libertad del que es una manifestación exige que las limitaciones que a él se establezcan respondan a supuestos derivados de la Constitución y que en cada caso resulte indubitablemente probado que se ha traspasado efectivamente el ámbito de libertad constitucional fijado" (STC 59/1990). El legislador orgánico puede fijar condiciones específicas para el ejercicio del derecho de reunión por parte de los extranjeros que se encuentran en nuestro país sin la correspondiente autorización de estancia o residencia, siempre y cuando respete un contenido del mismo que la Constitución salvaguarda por pertenecer a cualquier persona, independientemente de la situación en que se encuentre.

De ello, deduce el TC que la nueva redacción dada por el precepto impugnado al art. 7.1 de la Ley Orgánica 4/2000 no realiza una modulación del derecho de reunión, estableciendo condiciones a su ejercicio, sino que niega este derecho a los extranjeros que no dispongan de autorización de estancia o residencia en España. Esta regulación legal vulnera el art. 21 CE en su contenido constitucionalmente declarado por los textos a los que se refiere el art. 10.2 CE, y, en consecuencia, debe declararse inconstitucional el art. 7.1 de la Ley Orgánica 4/2000, de 11 de enero, en la nueva redacción que la da el art. 1, punto 5, de la Ley Orgánica 8/2000, de 22 de diciembre (STC 236/2007, de 7 de noviembre).

\section{I.2.2. El derecho de asociación}

Se impugna la redacción del art. 8 de la Ley Orgánica 4/2000, dada por el punto 6 del artículo primero de la Ley impugnada, que dispone:

"Todos los extranjeros tendrán el derecho de asociación, conforme a las leyes, que lo regulan para los españoles y que podrán ejercer cuando obtengan autorización de estancia o residencia en España".

El TC ha venido destacando que el contenido fundamental del derecho de asociación se manifiesta en tres dimensiones o facetas complementarias: la libertad de creación de asociaciones y de adscripción a las ya creadas; la libertad de no asociarse y de dejar de pertenecer a las mismas; y, finalmente, la 
libertad de organización y funcionamiento internos sin injerencias públicas. Junto a este triple contenido, el derecho de asociación tiene también una cuarta dimensión, esta vez "ínter privatos", que garantiza un haz de facultades a los asociados, considerados individualmente, frente a las asociaciones a las que pertenezcan o en su caso a los particulares respecto de las asociaciones a las cuales pretendan incorporarse (STC 104/1999).

Al igual que el derecho de reunión y manifestación, el derecho de asociación es un derecho esencial de cualquier sociedad democrática por cuanto fortalece las estructuras democráticas de la sociedad, lo que revierte en el fortalecimiento de todas las instituciones democráticas y contribuyen a la presencia de la diversidad cultural. Esta es la idea que parece recogerse en el art. $11 \mathrm{CEDH}$ y que ha aceptado el TEDH al considerar los derechos de reunión, manifestación y asociación y sindicación a la luz del art. 10 del citado Convenio, que establece la libertad de expresión ${ }^{3}$, entendiendo que un individuo no gozará de su libertad de asociación si las posibilidades de elección o de acción que le quedan se perciben como inexistentes o reducidas hasta el punto de no se le dé utilidad ninguna, hecho que sucede a la vista de la L.O. $8 / 2000$, puesto que hablar de derechos que no se pueden ejercitar es un absurdo jurídico.

Para el TC, el derecho de asociación se encuentra vinculado a la dignidad humana y al libre desarrollo de la personalidad por cuanto protege el valor de la sociabilidad como dimensión esencial de la persona y en cuanto elemento necesario para la comunicación pública en una sociedad democrática. Dado que se trata de un derecho cuyo contenido está unido a esa dimensión esencial, la Constitución y los tratados internacionales lo "proyectan universalmente" y de ahí que no sea constitucionalmente admisible la negación de su ejercicio a los extranjeros que carezcan de la correspondiente autorización de estancia o residencia en España. Ello no significa, que se trate de un derecho absoluto, y por ello el legislador puede establecer límites a su ejercicio por parte de cualquier persona, siempre que respete su contenido constitucionalmente declarado.

Estas consideraciones conducen al TC, a la conclusión de que la nueva redacción dada al art. 8 de la Ley Orgánica 4/2000 por el art. 1, punto 6, de la Ley impugnada, al excluir cualquier ejercicio de este derecho por parte de los extranjeros que carecen de autorización de estancia o residencia en España ha vulnerado el art. $22 \mathrm{CE}$ en su contenido constitucionalmente declarado por los textos a los que se refiere el art. 10.2 CE. En consecuencia, debe declararse inconstitucional el art. 8 de la Ley Orgánica 4/2000, de 11 de enero, en la redacción que le da el art. 1, punto 6, de la Ley Orgánica 8/2000, de 22 de diciembre... (STC 236/2007, de 7 de noviembre)

3 SSTEDH, de 13 de agosto de 1972, Caso Young y otros vs. Reino Unido; de 20 de septiembre de 1994, Caso Otto Preimnger Institut vs. Austria; de 26 de septiembre de 1995, Caso Vogt, vs. RFA; de 30 de enero de 1998, Caso Partido Comunista Unificado de Turquía y otros vs. Turquía), y esta libertad debe de garantizarse a toda persona bajo la jurisdicción del Estado parte por ser titulares "las personas" STEDH, de 8 de junio de 1976, Caso Engels y otros vs. Paises Pajos) 


\section{I.2.3. El derecho a la educación.}

El tercer precepto impugnado es el punto 7 del artículo primero de la Ley recurrida en este proceso, que da nueva redacción al apartado 3 del art. 9 de la Ley Orgánica 4/2000 . El precepto dispone:

"Los extranjeros residentes tendrán derecho a la educación de naturaleza no obligatoria en las mismas condiciones que los españoles. En concreto, tendrán derecho a acceder a los niveles de educación y enseñanza no previstos en el apartado anterior y a la obtención de las titulaciones que correspondan al caso, y al acceso al sistema público de becas y ayudas"

por considerar que esta nueva redacción vulneraría el art. 27.1 CE en relación con el art. 39.4 CE, el art. 28 de la Convención de las Naciones Unidas sobre Derechos del Niño, y el art. 26 de la Declaración Universal de los Derechos Humanos al impedir el acceso a la enseñanza no básica a los extranjeros menores de 18 años que no tengan residencia legal en España. El derecho del niño a ser escolarizado consagrado en el art. 27.1 CE comprendería tanto la enseñanza básica como la no básica (art. 1 Ley Orgánica 2/2006, del Derecho a la Educación), que formaría parte del contenido esencial de este derecho.

El derecho a la educación constituye un derecho fundamental vinculado a la dignidad humana que tiene por objeto «el libre desarrollo de la personalidad" (art. $27 \mathrm{CE}$ ), lo que, a tenor del artículo 10.1 CE constituye uno de los fundamentos del orden político y de la paz social.

La CE atribuye genéricamente a «todos «el derecho a la educación, por considerar que como derecho del ser humano debe ser abarcado con la mayor generosidad. Además, tiene por objeto: el pleno desarrollo de la personalidad; la formación en el respeto de los derechos y libertades fundamentales y en el ejercicio de la tolerancia y la libertad dentro de los principios democráticos de convivencia; la preparación para participar activamente en la vida social y cultural y la formación para la paz, la cooperación y la solidaridad entre pueblos (art. 2 L.O..E; art. 1.1 LOGSE; art. 26.2 DUDH y art. 13 PIDESC).

Como indica el TC en esta sentencia, de las disposiciones transcritas se deduce la inequívoca vinculación del derecho a la educación con la garantía de la dignidad humana, dada la innegable trascendencia que aquélla ad-

4 Como ha indicado el TC, el examen del apartado impugnado debe hacerse leyéndolo conjuntamente con el apartado 1 del art. 9 de la Ley Orgánica 4/2000, objeto también de una nueva redacción por el art. 1, punto 7 de la Ley recurrida, cuya inconstitucionalidad no se ha denunciado. Este precepto dispone: "Todos los extranjeros menores de dieciocho años tienen derecho $y$ deber a la educación en las mismas condiciones que los españoles, derecho que comprende el acceso a la enseñanza básica, gratuita y obligatoria, a la obtención de la titulación académica correspondiente y al acceso al sistema de becas y ayudas". El apartado 1 del art. 9 no exige pues la condición de "residente" para ejercer el derecho a la educación cuando se trate de la enseñanza básica, a la que pueden acceder todos los extranjeros menores de dieciocho años. Por el contrario, el apartado impugnado sí exige aquel requisito cuando se trate de la educación no obligatoria, sin hacer ninguna referencia a la edad. 
quiere para el pleno y libre desarrollo de la personalidad, y para la misma convivencia en sociedad, que se ve reforzada mediante la enseñanza de los valores democráticos y el respeto a los derechos humanos, necesarios para "establecer una sociedad democrática avanzada", como reza el Preámbulo de nuestra Constitución.

Dos problemas plantean la nueva regulación. En primer lugar, respecto a la enseñanza básica y obligatoria, que parece ser el contenido que la Ley reconoce como derecho a la educación de todos los menores de 18 años, ésta, comprende la educación primaria y la educación secundaria obligatoria, que abarca hasta los 16 años, con lo que el problema se plantearía con la posibilidad de cursar estudios de Bachillerato, que no son básicos ni obligatorios, y que abarcan el período de 2 años, entre los 16 y los 18 años. Sin embargo debemos de considerar que el derecho a la educación de que disponen los inmigrantes menores, al margen de que su situación de estancia sea o no regular, por reconocerse hasta los 18 años, deberá abarcar el bachillerato y la Formación Profesional de acuerdo con el contenido literal de la Constitución, tanto por mandato del art. 27, como por el art. 39.4 CE en relación con el art. 28.1.c del Convenio de Naciones Unidas sobre los derechos del Niño, que establece que los Estados tienen la obligación de hacer la enseñanza superior accesible a todos, sobre la base de la capacidad del menor y no sobre ninguna otra circunstancia, como puede ser la situación administrativa, así como por motivo del art. 13 PIDESC y los arts, 2, 7 y 26 DUDH. Además, esta educación deberá tener en cuenta el reconocimiento y respeto a la identidad cultural de los alumnos.

Como hemos defendido anteriormente, el reconocimiento efectivo del alcance universal del derecho a la educación es fundamental, de manera que el legislador no puede limitar el derecho a la educación en función de la edad y la situación administrativa del inmigrante. ${ }^{5}$

El segundo aspecto que ha motivado algunos recelos respecto a su adecuación con los mandatos constitucionales lo constituye el art. 9.3 que reduce la enseñanza no obligatoria a los extranjeros residentes, lo que implica despojar a los inmigrantes no residentes de este derecho, no pudiendo disfrutar, tampoco, del derecho a la educación básica cuando no fueran menores de 18 años.

El TC, establece, cómo de las disposiciones constitucionales relativas al derecho a la educación, interpretadas de conformidad con la Declaración Universal de Derechos Humanos y los Tratados y acuerdos internacionales referidos, se deduce que el contenido constitucionalmente garantizado de ese derecho, en su dimensión prestacional, no se limita a la enseñanza básica, sino que se extiende también a los niveles superiores, aunque en ellos no se imponga constitucionalmente la obligatoriedad y la gratuidad.

Por otra parte, también de las disposiciones examinadas y de su recta interpretación se obtiene que el derecho a la educación garantizado en el art.

5 Goig Martínez, J.M.- Derechos y libertades de los inmigrantes en España. Una visión constitucional, jurisprudencial y legislativa, Madrid, Universitas Internacional, 2004, pág 145. 
27.1 CE corresponde a "todos", independientemente de su condición de nacional o extranjero, e incluso de su situación legal en España. Esta conclusión se alcanza interpretando la expresión del art. 27.1 CE de acuerdo con los textos internacionales citados, donde se utilizan las expresiones "toda persona tiene...", o "a nadie se le puede negar..." el derecho a la educación. El acceso a los establecimientos escolares y el derecho a utilizar, en principio, los medios de instrucción que existan en un momento determinado, debe garantizarse, de acuerdo con el art. 1 CEHD, «a toda persona dependiente de la jurisdicción de un Estado contratante". Esta expresión contenida en el art. $1 \mathrm{CEDH}$, interpretada conjuntamente con el art. $14 \mathrm{CEDH}^{6}$, debe entenderse que incluye también a aquellas personas no nacionales que se encuentren en una situación irregular o ilegal.

En definitiva, para el TC, el contenido constitucionalmente declarado por los textos a los que se refiere el art. 10.1 CE del derecho a la educación garantizado en el art. 27.1 CE incluye el acceso no sólo a la enseñanza básica, sino también a la enseñanza no obligatoria, de la que no pueden ser privados los extranjeros que se encuentren en España y no sean titulares de una autorización para residir. El precepto impugnado impide a los extranjeros menores de dieciocho años sin autorización de estancia o residencia acceder a la enseñanza secundaria postobligatoria. Ese derecho de acceso a la educación no obligatoria de los extranjeros menores de edad forma parte del contenido del derecho a la educación, y su ejercicio puede someterse a los requisitos de mérito y capacidad, pero no a otra circunstancia como la situación administrativa del menor. Por ello, declara la inconstitucionalidad del inciso "residentes" del art. 9.3 de la Ley Orgánica 4/2000, de 11 de enero, en la redacción dada por el art. 1, punto 7, de la Ley Orgánica 8/2000, de 22 de diciembre." (STC 236/2007, de 7 de noviembre)

\section{I.2.4. El derecho de sindicación.}

El Parlamento de Navarra impugna el punto 9 del artículo primero de la Ley recurrida en este proceso, que da nueva redacción al art. 11.1 de la Ley Orgánica 4/2000, que dispone:

"Los extranjeros tendrán derecho a sindicarse libremente o a afiliarse a una organización profesional, en las mismas condiciones que los trabajadores españoles, que podrán ejercer cuando obtengan autorización de estancia o residencia en España".

por considerar que vulnera el contenido esencial del derecho reconocido en el art. 28.1 CE y ser contrario a lo establecido en el art. 23.4 de la Declaración Universal de los Derechos Humanos, al art. 22 del Pacto Internacional de Derechos Civiles y Políticos, y al art. 11 del CEDH, y considerar que el ejercicio

6 Caso Irlanda contra Reino Unido, de 18 de enero de 1978, \238; Caso Príncipe HansAdams II de Lichtenstein, de 12 de julio de 2001, \ 46 
del derecho a la libertad sindical no requeriría la condición laboral de su titular, y por ello no cabría argumentar que los titulares del derecho sean sólo los trabajadores.

Entendemos que el concepto de trabajador que recoge la Constitución es mucho más amplio que el fijado por la L.O. 8/2000, reducido a los extranjeros que dispongan de un permiso de trabajo y residencia, ley que , además, parece reconocer esta misma afirmación y la propia existencia de una relación laboral para el supuesto que estamos estudiando cuando en su art. 36 manifiesta:

"Los empleadores que deseen contratar a un extranjero no autorizado para trabajar, deberán obtener previamente, conforme a lo dispuesto en el apartado 1 de este artículo, autorización del Ministerio de Trabajo y Asuntos Sociales. La carencia de la correspondiente autorización por parte del empleador, sin perjuicio de las responsabilidades a que dé lugar, no invalidará el contrato de trabajo respecto a los derechos del trabajador extranjero"

La jurisprudencia del TC ha vinculado "...la titularidad del derecho de libertad sindical a "todos" los trabajadores en su caracterización material, y no jurídico-formal, y a "todos" los sindicatos (art. 28.1 en relación con el art. 7 $\mathrm{CE}$ ), entendiendo de este modo la proyección universal subjetiva que de dicho derecho efectúan los tratados internacionales, entre los cuales es de recordar el Convenio 87 de la OIT relativo a la libertad sindical y a la protección del derecho de sindicación, cuyo art. 2 reconoce a todos los trabajadores, sin distinción alguna y sin autorización previa, los derechos de fundación de sindicatos y de afiliación a los mismos. Siendo así, no resulta constitucionalmente admisible la exigencia de la situación de legalidad en España para su ejercicio por parte de los trabajadores extranjeros, aunque lo sea para la celebración válida de su contrato de trabajo, y, en consecuencia, para la obtención de la condición jurídico-formal de trabajador —art. 38 de la Ley Orgánica 4/2000, y arts. $1.1,7$ c) y 9.2 del Texto Refundido de la Ley del Estatuto de los Trabajadores, aprobado Real Decreto Legislativo 1/1995, de 24 de marzo-. Por supuesto, ello no significa que el legislador orgánico no pueda establecer limitaciones o excepciones a su ejercicio en los términos a los que ya se refiere el propio art. 28.1 CE. Pero no alcanzando tales limitaciones o excepciones a los trabajadores extranjeros, la exclusión total del derecho de libertad sindical de aquellos extranjeros que trabajen pese a no haber obtenido autorización de estancia o residencia en España, no se compadece con el reconocimiento del derecho de libertad sindical que efectúa el art. 28.1 CE interpretado conforme a la normativa internacional sobre este derecho ratificada por España. Tampoco se compadece con este derecho la limitación consiguiente que deriva para el derecho de los sindicatos de defender y promover los intereses de estos trabajadores."

Como consecuencia de estos argumentos, para el TC, la concepción según la cual el derecho de libertad sindical se ejercería exclusivamente por quienes ostentan la condición de trabajador en sentido legal, es decir, por quienes "sean sujetos de una relación laboral" (en los términos del art. 1.2 
LOLS), no se corresponde con la titularidad del derecho fundamental, ejercitable, entre otras finalidades posibles en la defensa de los intereses de los trabajadores, para llegar a ostentar tal condición jurídico-formal. De ahí que no resulte absurdo, reconocer este concreto derecho a los extranjeros no autorizados para estar o residir en España, quienes pueden afiliarse a los Sindicatos españoles para la defensa de sus intereses, entre los que puede encontrarse la regularidad de su situación, pese a la irregularidad de la misma. También aquí, el TC precisa que el legislador orgánico puede fijar condiciones específicas para el ejercicio del derecho de sindicación por parte de los extranjeros que se encuentran en nuestro país sin la correspondiente autorización de estancia o residencia, siempre y cuando respete un contenido del mismo que la Constitución salvaguarda por pertenecer a cualquier persona, independientemente de la situación en que se encuentre.

Los razonamientos anteriores conducen a la inconstitucionalidad del art. 11.1 de la Ley Orgánica 4/2000, de 11 de enero, en la redacción dada por el art. 1, punto 9, de la Ley Orgánica 8/2000, de 22 de diciembre, por ser contrario al art. 28.1 CE. (STC 236/2007, de 7 de noviembre). Sin embargo, la inconstitucionalidad de ese inciso viene referida exclusivamente al derecho a sindicarse libremente, con los efectos que se expondrán en el último apartado de este estudio.

\section{I.2.5. El derecho a la huelga.}

Respecto al derecho a la huelga, tanto la Constitución en su art. 28.2 lo reconoce a "los trabajadores para la defensa de sus intereses", como los Tratados Internacionales vinculan el ejercicio de este derecho a la condición de trabajador. La Carta Social Europea reconoce en su art. 6.4 «El derecho de los trabajadores y de los patronos, en caso de conflicto de intereses, a recurrir a acciones colectivas, incluso el derecho de huelga" y el artículo 8.1 PIDES garantiza "el derecho de huelga, ejercido de acuerdo con las leyes de cada país".

El concepto de trabajador, relevante para la determinación del ámbito subjetivo del derecho de huelga, ha de entenderse, en línea con lo que ha afirmado el TC en la STC 236/ 2007 en relación con el derecho a la libertad sindical del trabajador extranjero, en su caracterización material, independientemente de la legalidad o ilegalidad de su situación, de suerte que en ella ha de incluirse a todo aquel que presta sus servicios retribuidos por cuenta ajena y dentro del ámbito de organización y dirección de otra persona. Siendo ello así no resulta constitucionalmente admisible la exigencia de la situación de legalidad en España para el ejercicio del derecho de buelga por parte de los trabajadores extranjeros, aunque la anterior situación resulte exigible para la celebración válida de su contrato de trabajo — art. 38 de la Ley Orgánica 4/2000, y arts. 1.1 y 7 c) texto refundido de la Ley del estatuto de los trabajadores, aprobado Real Decreto Legislativo 1/1995, de 24 de marzo-.

Como ha indicado el TC, el propio párrafo segundo del apartado 3 del art. 36 de la misma Ley Orgánica 4/2000, en la redacción dada por el art. 1.29 de la Ley Orgánica 8/2000, sienta el criterio en cuya virtud la carencia de la 
correspondiente autorización para trabajar no invalida el contrato de trabajo respecto a los derechos del trabajador extranjero. De esta forma el propio legislador orgánico, con tal declaración de equiparación, pretende proteger los derechos del trabajador extranjero que, aun careciendo de autorización administrativa para trabajar, está efectivamente trabajando en nuestro país. Tales derechos no se atribuyen a la persona en razón de su nacionalidad o de la situación administrativa en la que puede encontrarse en un momento determinado, sino sólo por el hecho de ser trabajador. Entre esos derechos básicos se encuentra - art. 4.1 e) del Estatuto de los trabajadores- el de huelga. Por ello en relación con tal derecho ninguna duda puede caber respecto a que el mismo, de titularidad individual y ejercicio colectivo, se encuentra dentro de los medios legítimos para la defensa de los intereses de los trabajadores, concepto éste más amplio que el de derechos, de forma que no resulta constitucionalmente admisible que se prive al trabajador de una protección cuya razón de ser es la propia defensa de sus intereses.

"Así pues la exclusión total del derecho de huelga de aquellos extranjeros que trabajen a pesar de carecer de la correspondiente autorización administrativa para ello - la cual, por lo demás, no están personalmente obligados a solicitar- no se compadece con el reconocimiento del derecho de huelga que proclama el art. 28.2 CE, interpretado conforme a la normativa internacional sobre este derecho ratificada por España, en particular el art. 8.1 d) PIDESC, en cuya virtud los Estados signatarios del Pacto han de garantizar el ejercicio del derecho de huelga, de forma que la regulación que se establezca deberá tener por objeto el ejercicio del derecho y no impedirlo a los trabajadores que prestan servicios retribuidos por cuenta ajena sin contar con los preceptivos permisos legales. (STC 259/2007, de 19 de diciembre, F.J.7)

La concepción criticada no se corresponde con la titularidad del derecho fundamental ejercitable en la defensa de los intereses de los trabajadores, entre los que puede encontrarse la consecución de la plena regularidad de su situación administrativa. De ahí que no resulte absurdo (...), reconocer este concreto derecho a los extranjeros no autorizados administrativamente para trabajar en España, quienes pueden ejercerlo para la defensa de sus intereses, entre los que puede encontrarse la regularidad de su situación, pese a la irregularidad de la misma. De esta forma la norma aquí controvertida no garantiza la debida protección de los intereses que, a través del reconocimiento constitucional del derecho de huelga, se tratan de satisfacer.

En consecuencia, declara la inconstitucionalidad del inciso "cuando estén autorizados a trabajar" del art. 11.2 de la Ley Orgánica 4/2000, de 11 de enero, en la redacción dada por el art. 1, punto 9, de la Ley Orgánica 8/2000, de 22 de diciembre, por ser contrario al art. 28.2 CE. (STC 259/2007, de 19 de diciembre)

I.2.6. El derecho a la tutela judicial efectiva.

Ni del reconocimiento constitucional que hace el art. $24 \mathrm{CE}$, ni de la jurisprudencia constitucional al afirmar que la vinculación del derecho a la tute- 
la judicial efectiva a la dignidad humana es imprescindible, no solo por la dicción literal del precepto constitucional, sino porque a esa misma conclusión se llega interpretándolo, según exige el art. 10.2 CE, de conformidad con el art. 10 de la DUDH; con el art. 6.1 del Convenio de Roma y con el art. 14.1 del PIDCP, se puede permitir diferencia de trato entre nacionales y extranjeros en lo que a este derecho se refiere, lo que ha sido reconocido por el art. 20 L.O.8/2000 que equipara en tratamiento a españoles y extranjeros en titularidad y ejercicio en este derecho, y extiende, con carácter general, a los procedimientos administrativos en materia sobre extranjería, las garantías previstas en la legislación general sobre procedimiento administrativo. Sin embargo se establecen algunas excepciones en este tratamiento paritario que afectan, tanto al procedimiento administrativo como a la vía judicial, y que pueden afectar al derecho fundamental a la tutela judicial efectiva y al derecho a la defensa.

En tres ocasiones, las partes recurrentes consideran inconstitucional la regulación de la LO 8/2000 por violación del art. 24 CE.

1. En primer lugar, se impugna el punto 16 del artículo primero de la Ley Orgánica 8/2000 que da nueva redacción al apartado 2 del art. 22 (antes 20) de la Ley Orgánica 4/2000, y dispone:

"Los extranjeros residentes que acrediten insuficiencia de recursos económicos para litigar tendrán derecho a la asistencia jurídica gratuita en iguales condiciones que los españoles en los procesos en los que sean parte, cualquiera que sea la jurisdicción en la que se sigan".

El precepto se estima contrario al art. 119 CE en relación con el art. 24.1 CE, así como a los arts. 2 y 10.1 CE, al art.10 de la Declaración Universal de los Derechos Humanos, al art. 14.1 del Pacto Internacional de Derechos Civiles y Políticos, y al art. 6.1 del $\mathrm{CEDH}$, porque introduce una limitación a un derecho prestacional y de configuración legal — la asistencia jurídica gratuita- que forma parte del contenido esencial del derecho a la tutela judicial (art. 24 CE), y supone de facto impedir el acceso a la jurisdicción y el derecho a la tutela judicial efectiva de aquellos extranjeros no residentes que carezcan de recursos para litigar.

El art. 22.2 L.O 8/2000, suprime el derecho a la asistencia gratuita a los inmigrantes no residentes, salvo en aquellos procedimientos que puedan llevar aparejada la no entrada, la expulsión o devolución y en los procesos de asilo. Se trata de una limitación que contraviene el derecho a la defensa proclamado en el art. 24 CE.

El derecho a la asistencia jurídica gratuita garantizado por el art. 119 CE a quienes acrediten insuficiencia de recursos para litigar, a pesar de su naturaleza prestacional y de que, como derecho de configuración legal corresponde al legislador determinar su contenido y condiciones de ejercicio (STC 16/1994) "no puede ser denegado sin vulnerar al mismo tiempo su derecho de acceso a la jurisdicción (STC 117/1998) a quienes, cumpliendo los requisitos legalmente establecidos lo soliciten" (STC 144/2001), puesto que el art. 119 CE 
consagra un derecho de acceso a la jurisdicción reconocido en el art. 24.1 CE cuya" finalidad inmediata radica en permitir el acceso a la justicia para interponer pretensiones $u$ oponerse a ellas a quienes no tienen medios económicos suficientes para ello, y, más ampliamente, trata de asegurar que ninguna persona quede procesalmente indefensa por carecer de recursos para litigar, (STC 138/1988).

Aunque del propio texto del inciso primero del art. 119 se desprende que no nos hallamos ante un derecho absoluto e ilimitado, y en consecuencia el legislador podrá atribuir el beneficio de justicia a quienes reúnan las características y requisitos que considere relevantes, podrá modular la gratuidad en función del orden jurisdiccional afectado o incluso del tipo concreto de proceso y por supuesto en función de los recursos económicos de los que pueda disponer en cada momento (STC 16/1994), "la amplia libertad de configuración legal que resulta del art. 119 no es, sin embargo absoluta, pues el inciso segundo de dicho precepto explicitamente declara que la gratuidad de la justicia se reconocerá en todo caso respecto de quienes acrediten insuficiencia de medios para litigar, existiendo, por consiguiente, un contenido constitucional indisponible para el legislador que obliga a reconocer el derecho a la justicia gratuita a quienes acrediten insuficiencia de recursos económicos para litigar. "El art 119 tiene como contenido esencial indisponible, que la justicia gratuita debe reconocerse a quienes no puedan hacer frente a los gastos originados por el proceso sin dejar de atender a sus necesidades vitales y a las de su familia, al objeto de que nadie quede privado del acceso a la justicia. Dicho en otras palabras, a quienes de exigirse el pago de los gastos procesales, se verian en la alternativa de dejar de litigar o poner en peligro el nivel mínimo de subsistencia personal o familiar, (STC 117/1998)

Este criterio que defendemos es el adoptado por el TC en STC 95/2003, en el que se resuelve el recurso de inconstitucionalidad presentado por el Defensor del Pueblo contra el art. 2 de la Ley 1/1996, de 10 de enero de asistencia jurídica gratuita (LAJG) cuando reconoce el derecho en cuestión "a los extranjeros que residan legalmente en Españan. Si el derecho a la asistencia gratuita sólo se reconoce con plenitud a los extranjeros legalmente residentes, los que se encuentran ilegalmente sólo gozan de asistencia letrada y asistencia y representación gratuitas en determinados procesos, de manera que quedan fuera de la cobertura del derecho de asistencia jurídica gratuita todas aquellas cuestiones que afectan al estatus personal de los extranjeros que no residan legalmente y que no guarden relación con los supuestos contemplados legalmente.

En esta sentencia el TC, manifiestó que «la expresión "que residan (En España) habrá de entenderse referida a la situación puramente fáctica de los que se hallan en territorio español, sin que quepa atribuir a la referida expresión un significado técnicamente acuñado de residencia autorizada administrativamente", para afirmar , a continuación, y respecto a la extensión de los procesos en que resulta reconocido el derecho a la asistencia jurídica gratuita como consecuencia de la parcial declaración de inconstitucionalidad del precepto impugnado que : "al apreciarse inconstitucionalidad en la exigencia 
del requisito de la legalidad de residencia, los extranjeros que se encuentren en España y reúnan las condiciones requeridas legalmente para ello, podrán acceder a la asistencia jurídica gratuita en relación con cualquier tipo de procesos a efectos del cual gocen de la precisa legitimación"

La aplicación de esta jurisprudencia al enjuiciamiento del art. 22.2 de la Ley Orgánica 4/2000, modificado por la Ley aquí impugnada, lleva directamente al TC a apreciar su inconstitucionalidad (STC 236/2007, de 7 de noviembre)

2. Otro de los aspectos de la L.O. 8/2000 que puede vulnerar las garantías derivadas del procedimiento administrativo en materia de extranjería viene referido al juego que se da entre los arts. 20.2 y 27 , respecto a la motivación de la denegación de visado.

La ausencia de motivación, además de por vía de los preceptos 9.3 y 106.1 CE, puede atentar contra el art. 24 porque la motivación de las resoluciones administrativas constituye la única vía de exteriorización y formación de la voluntad administrativa respecto a la solicitud rechazada y una de las principales formas de control jurisdiccional de la legalidad del acto de denegación.

Así, se impugna el punto 14 del artículo primero de la Ley Orgánica 8/2000, que da nueva redacción al inciso final del apartado 2 del art. 20 (antes 18), disponiendo:

"Los procedimientos administrativos que se establezcan en materia de extranjería respetarán en todo caso las garantías previstas en la legislación general sobre procedimiento administrativo, especialmente en lo relativo a publicidad de normas, contradicción, audiencia al interesado y motivación de las resoluciones, salvo lo dispuesto en el art. 27 de esta Ley."

y se recurre asimismo la nueva redacción dada por la Ley Orgánica 8/2000 al apartado 5 del art. 27 (antes 25) de la Ley Orgánica 4/2000, que establece:

"La denegación de visado deberá ser motivada cuando se trate de visados de residencia para reagrupación familiar o para el trabajo por cuenta ajena...

puesto que los preceptos transcritos permiten que no se motive el acuerdo de denegación de visado en algunos supuestos, en concreto, cuando no se refieran a la reagrupación familiar o a la solicitud de permiso de trabajo por cuenta ajena. De ahí que se reputen contrarios a los arts. 24.1 en relación con el art. 9.3 y 106.1 CE, ya que no se exige la motivación de una resolución administrativa, impidiendo su control jurisdiccional, lo que supone un menoscabo del derecho de defensa, además de alentar el carácter arbitrario de las decisiones de la Administración? ${ }^{7}$.

7 En el ámbito administrativo, y pesar de que el TC ha considerado que la tutela judicial efectiva sólo se predica de la actuación judicial, y no puede ser invocado frente a actuaciones de 
Como indica el TC, la exoneración del deber de motivación de los actos administrativos denegatorios del visado establecida en aquellos preceptos, no debe reputarse contraria al art. 24.1 CE puesto que se trata de actos que no imponen sanción alguna ni limitan el ejercicio de ningún derecho fundamental. Por otra parte, aquella exoneración tampoco debe considerarse incompatible con la interdicción de la arbitrariedad de los poderes públicos (art. 9.3 CE) y con el obligado control de la actuación administrativa por parte de los Tribunales (art. 106.1 CE), que la Ley aquí enjuiciada garantiza "en todo caso, cuando el extranjero no se encuentre en España" (art. 65.2).

La inconstitucionalidad del precepto sólo podría sostenerse si la norma impugnada hubiera impedido el control jurisdiccional de estos actos administrativos basándose en su carácter potestativo o discrecional pues "con dicha fundamentación se niega la proyección que en este ámbito tiene la propia interdicción de la arbitrariedad de los poderes públicos que proclama el art. 9.3 CE" (STC 163/2002, de 16 de septiembre, FJ 5). Pero la Ley enjuiciada somete a control de los Tribunales esta actividad administrativa (art. 106.1 CE), con lo cual la Administración deberá estar en todo momento en condiciones de explicar que no ha ejercido de forma arbitraria sus facultades discrecionales.

3. El tercer aspecto que puede afectar, por vía administrativa, al derecho constitucional a la defensa, lo constituye el "Procedimiento preferente de expulsión de extranjeros" regulado en el art. 63 de la Ley, por virtud de la cual se establece la ejecución inmediata de la sanción administrativa de expulsión. Por ello, la última impugnación del recurso de inconstitucionalidad se dirige al punto 56 del artículo primero de la Ley Orgánica 8/2000, que establece:

"Cuando de las investigaciones se deduzca la oportunidad de decidir la expulsión, se dará traslado de la propuesta motivada por escrito al interesado, para que alegue lo que considere adecuado, en el plazo de cuarenta y ocho horas. En los supuestos en que se haya procedido a la detención preventiva del extranjero, éste tendrá derecho a la asistencia letrada que se le proporcionará de oficio, en su caso, y a ser asistido por intérprete, y de forma gratuita en el caso de que careciese de medios económicos."

La posible inconstitucional se aduce porque el plazo de cuarenta y ocho horas que se otorga al interesado para formular alegaciones en su defensa, tras la incoación del procedimiento sancionador, vulnera el art. 24 CE en relación con el art. 6 del CEDH al producir indefensión, como se desprendería de la jurisprudencia del TEDH por la indefensión que causaría la brevedad del plazo para alegaciones establecido en el precepto impugnado.

la Administración (SSTC 175/1987; 197/1988; 243/1988), existen numerosas sentencias del TS que ponen de manifiesto que las cuestiones de extranjería deberán solventarse mediante un procedimiento que respete totalmente las garantías implícitas en el art. 24 CE (SSTS de 27 de mayo de 1991; de 25 de febrero de 1992, entre otras). La sentencia del Tribunal Supremo de 12 de noviembre de 1992 manifiesta que el derecho a un procedimiento administrativo debe ostentar todas las garantías por ser una de las manifestaciones del derecho a la tutela judicial efectiva. 
El TC, en la sentencia en comentario, indica que la regulación de este procedimiento no puede reputarse contraria al art. $24 \mathrm{CE}$. Ciertamente se trata de un procedimiento administrativo sancionador, ya que en estos casos la expulsión es "consecuencia de una conducta tipificada como infracción administrativa" (STC 116/1993, FJ 3), y por consiguiente le son aplicables los principios esenciales reflejados en el art. $24 \mathrm{CE}$ "en la medida necesaria para preservar los valores esenciales que se encuentren en la base del precepto y la seguridad jurídica que garantiza el art. 9 CE" (desde la STC 18/1981, de 8 de junio), entre ellos el que proscribe cualquier indefensión (SSTC 7/1998, de 13 de enero; 14/1999, de 22 de febrero).

Ahora bien, la pretendida indefensión que generaría el precepto no es tal, pues como reitera el TC, la brevedad de los plazos no implica "per se" la vulneración del derecho a la tutela judicial efectiva si con ello se tiende a hacer efectivo el principio de celeridad en el proceso, ya que es constitucionalmente inobjetable que el legislador prevea tal reducción en los plazos cuando dicha decisión responde a una finalidad razonable y necesaria, acorde con los principios que han de regir el procedimiento correspondiente (SSTC 14/1992, de 10 de febrero; 335/1994, de 19 de diciembre; 130/1998, de 16 de junio; $85 / 2003$, de 8 de mayo). Tal es el caso de los supuestos previstos en el art. 63.1 de la Ley Orgánica 4/2000, con la consecuencia de que el plazo establecido en el art. 63.2 no pueda reputarse contrario al art. $24 \mathrm{CE}$.

Por otra parte, los extranjeros sometidos a este procedimiento preferente de expulsión disponen de las garantías esenciales del procedimiento administrativo, como el derecho de audiencia y el derecho a una resolución motivada, además del control judicial de la decisión que garantiza la misma Ley Orgánica al disponer que "las resoluciones administrativas sancionadoras serán recurribles con arreglo a lo dispuesto en las leyes" (art. 65, redactado conforme a la Ley Orgánica 8/2000).

En consecuencia, desestima el recurso de inconstitucionalidad, declarando que el referido precepto no es contrario al art. 24 CE (STC 259/2007, de 19 de diciembre).

\section{LA IMPORTANCIA DE LOS FALLOS, Y SUS CONSECUENCIAS}

\section{II.1. CONSIDERACIONES PREVIAS}

Con independencia del fallo, que posteriormente será examinado, la importancia de la STC 236/2007, de 7 de noviembre, y de las otras dictadas en recursos de inconstitucionalidad presentados contra la L.O 4/2000 en su versión dada por la L.O 8/2000, radica, principalmente, en constituir la primera vez en que el TC resuelve a cerca de la posible inconstitucionalidad de una ley que, reconociendo la titularidad de determinados derechos y libertades a los extranjeros, niega el ejercicio de determinados derechos, no a los extranjeros en general, sino solamente a aquellos que no dispongan de la autorización de estancia o residencia, exigida por la legislación de extranjería. 
El TC se plantea, de esta manera, si puede resultar constitucional que el legislador atienda a la situación administrativa de los extranjeros para configurar su situación jurídica, teniendo en consideración que la Constitución no distingue entre los extranjeros en función de la regularidad de su estancia o residencia.

Del análisis de la fundamentación jurídica que realiza el TC, se fija la posición del legislador a la hora de proceder a una regulación de esta naturaleza.

Como indica el TC, :

1. La Constitución constituye el parámetro para la fijación del estatus de los derechos y libertades del inmigrante.

De ello, debemos deducir que, en cuanto parámetro primero y primario para la determinación de este estatus, el artículo 13 CE no constituye el único precepto que determina de qué derechos y libertades son titulares los inmigrantes que se encuentran en territorio español, ni cómo podrán ser ejercidos. Por el contrario, una interpretación sistemática de la Norma Suprema implica que en la determinación de este estatus habrá que atenerse a la voluntad y el deseo de los constituyentes, expresado en el artículo 10.1 que convierte a la dignidad del hombre y los derechos que le son inherentes en fundamento del orden político y de la paz social, pero también, en el propio Preámbulo y en el artículo 1.1, tanto al definir el modelo de Estado, como al proclamar los valores superiores del ordenamiento jurídico —en especial la libertad y la igualdad-, así como en la sumisión y vinculación que para los poderes públicos suponen los derechos y libertades constitucionales, y los mandatos derivados de los artículos 9 y $53 \mathrm{CE}$, todo ello sin olvidar la posición que respecto a los derechos y libertades ocupan, como criterio interpretativo, los Tratados y Acuerdos Internacionales en materia de derechos, de los que España es parte, y que integran nuestro ordenamiento jurídico (art. $96 \mathrm{CE})^{8}$.

2. A esta última afirmación, dedica la STC 236/2007 sus reflexiones iniciales, en base al segundo argumento general en el que se fundamenta el recurso - aunque no se formula explícitamente-, que sostiene la inconstitucionalidad de la mayoría de los preceptos impugnados por su presunta contradicción con los Tratados Internacionales ratificados por España en materia de derechos y libertades.

La jurisprudencia del TC ha afirmado en reiteradas ocasiones la utilidad de los textos internacionales ratificados por España "para configurar el sentido y alcance de los derechos fundamentales, de conformidad con lo establecido en el art. 10.2 CE" (SSTC 38/1981; 84/1989). El significado de la "interpretación" a la que alude el art. 10.2 CE, "no convierte a tales tratados y acuerdos internacionales en canon autónomo de validez de las normas y actos de los poderes públicos desde la perspectiva de los derechos fundamentales - si así fuera, sobraría la proclamación constitucional de tales derechos, bastando con que el constituyente hubiera efectuado una remisión a las Declaraciones internacionales de derechos humanos o, en general, a los tratados que suscriba 
al Estado español sobre derechos fundamentales y libertades públicas-. Por el contrario, la validez de las disposiciones y actos impugnados en amparo debe medirse sólo por referencia a los preceptos constitucionales que reconocen los derechos y libertades susceptibles de protección en esta clase de litigios, siendo los textos y acuerdos internacionales del art. 10.2 una fuente interpretativa que contribuye a la mejor identificación del contenido de los derechos.

Sin embargo, como indica el TC, no podría concluirse que el legislador español, al regular los derechos de los extranjeros, no resulte limitado ex art. 10.2 CE por los Tratados Internacionales ratificados por España. El art. $13 \mathrm{CE}$ autoriza al legislador a establecer restricciones y limitaciones a los derechos de los extranjeros en España, pero sin afectar "al contenido delimitado para el derecho por (..) los Tratados Internacionales" (STC 242/1994), que debe observar para configurar el sentido y alcance de los derechos fundamentales. Como cualquier otro poder público, también el legislador está obligado a interpretar los correspondientes preceptos constitucionales de acuerdo con el contenido de dichos Tratados o Convenios, que se convierte así en el "contenido constitucionalmente declarado" de los derechos y libertades que enuncia el Capítulo segundo del Título I de nuestra Constitución (STC 236/2007, de 7 de noviembre)

3. El legislador contemplado en el art. $13 \mathrm{CE}$ se encuentra limitado al regular aquellos derechos que, «la Constitución reconoce directamente a los extranjeros".

4. El legislador no puede negar tales derechos a los extranjeros, aunque sí puede establecer "condicionamientos adicionales" respecto a su ejercicio por parte de aquéllos, si bien "ha de respetar, en todo caso, las prescripciones constitucionales, pues no puede estimarse aquel precepto [art. 13.1 CE] permitiendo que el legislador configure libremente el contenido mismo del derecho, cuando éste haya venido reconocido por la Constitución directamente a los extranjeros. (..). Una cosa es, en efecto, autorizar diferencias de tratamiento entre españoles y extranjeros, y otra entender esa autorización como una posibilidad de legislar al respecto sin tener en cuenta los mandatos constitucionales".

5. El mandato contenido en el precepto constitucional "constituye en puridad un contenido preceptivo del derecho que se impone al legislador en el momento de regular su ejercicio" por parte de los extranjeros. Para la identificación de estos derechos reconocidos ex constitutione a los extranjeros debe tenerse especialmente en cuenta, entre otros criterios, la dicción de los preceptos del Título I reconocedores de derechos, a los que remite el art. 13.1 $\mathrm{CE}$, pues en ellos se hace normalmente referencia a sus titulares utilizando distintas expresiones ("todos, "todas las personas", "los españoles", "nadie", "los ciudadanos") o también fórmulas impersonales ("se reconoce..", "se garantiza..").

6. El legislador goza, en cambio, de mayor libertad al regular los aquellos derechos que no son atribuidos directamente por la Constitución a los ex- 
tranjeros pero que el legislador puede extender a los no nacionales "aunque no sea necesariamente en idénticos términos que los españoles" (STC 94/1993) porque el art. 13.1 CE no dice, en efecto, que los extranjeros dispongan de los mismos derechos que los españoles, siendo precisamente ese precepto el que "en nuestra Constitución establece los límites subjetivos determinantes de la extensión de la titularidad de los derechos fundamentales a los no nacionales" (Declaración del Tribunal Constitucional de 1 de julio de 1992). Si bien aquella libertad "no es en modo alguno absoluta" (STC 94/1993).

7. Cuando los preceptos legales no se limitan a condicionar el ejercicio de derechos y libertades por parte de los extranjeros en situación irregular, sino que impiden su ejercicio de manera radical, se está negando el derecho o libertad (STC 236/2007, de 7 de noviembre)

A pesar de que de la nueva redacción dada a determinados preceptos de la L.O. 8/2000 se pone de manifiesto que la nacionalidad no afecta a la titularidad de estas libertades, puesto que los extranjeros son titulares de los mismos, solamente estando afectado su ejercicio, para el que se exige la autorización de estancia o residencia en España, la verdad es que la Ley ha creado una ficción jurídica de difícil encaje.

Como ha manifestado un importante sector de la doctrina ${ }^{9}$, reconocer la titularidad de un derecho y no su ejercicio, equivale a negar este derecho. Privar a los extranjeros en situación irregular de los derechos fundamentales de asociación, reunión y manifestación, educación, tutela judicial, sindicación y huelga, no sólo rompe el propio sistema de derechos, sino que se convierte en una agresión potencial para los derechos de todos los ciudadanos.

En el estudio del tratamiento que la L.O. 8/2000 otorga a los derechos y libertades de los inmigrantes, habrá que distinguir el que reciben aquellos derechos respecto de los cuales el legislador puede ejercer determinadas modulaciones, por estar autorizado para ello por vía constitucional, de aquellos otros derechos y libertades fundamentales reconocidos a todos por la propia Constitución y directamente vinculados a la dignidad humana y al libre desarrollo de la personalidad y respecto de los cuales la capacidad de restricción por el legislador está limitada por propio reconocimiento constitucional. La distinción entre los no nacionales que se encuentran en un Estado en situación regular de aquellos cuya estancia es irregular, es importante en relación con el derecho legítimo que puede corresponder a todo Estado de sancionar la entrada o permanencia irregular de inmigrantes y en orden a la consecuencia de su expulsión, pero una cosa muy distinta es que respecto de tales inmigrantes, los poderes públicos no tengan obligaciones reconocidas, tanto por la propia Constitución en su Título I, como internacionalmente, de manera que se pueda negar la protección de los derechos humanos de dichas

9 Entre otros, Aragón Reyes, M; Asensi Sabater;J; Biglinio Campos, P, o Carrillo, M, en sus respuestas a la encuesta sobre "La Ley de Extranjería y la Constitución" que plantea el n ${ }^{\circ} 7$ de la Revista Teoría y Realidad Constitucional, 2001. 
personas mientras se encuentran en el territorio del Estado, porque se encuentran bajo su jurisdicción, y el Estado debe de garantizar la protección de sus derechos humanos dentro del ejercicio, tanto de sus obligaciones constitucionales, como internacionales.

Y ello, sin olvidar que los Tratados Internacionales sobre la materia, con formar parte del ordenamiento interno cuando hayan sido válidamente celebrados y publicados, operan como criterio de interpretación de las disposiciones constitucionales en la materia (arts 96 y $12.2 \mathrm{CE}$ ). Los preceptos internacionales sobre derechos humanos imponen unas líneas de conducta, exigen a los Estados que obren de cierta manera y legitiman a los hombres para que luchen cuando sus derechos y libertades no son respetados ${ }^{10}$.

\section{II.2. CONTENIDO DEL FALlO Y EFECTOS DE LA SENTENCIA}

Los fallos del TC, a los que acompañan un Voto Particular que formula el Magistrado D. Vicente Conde Martín de Hijas ${ }^{11}$ (al que se adhiere el Magistrado D. Jorge Rodríguez-Zapata Pérez), y un Voto particular de adhesión al primero (STC 236/2007) formulado por el Magistrado D. Roberto García-Calvo y Montiel, estiman parcialmente los recurso de inconstitucionalidad, interpuestos contra la Ley Orgánica 8/2000, de 22 de diciembre, de reforma de la Ley Orgánica 4/2000, de 11 de enero, sobre Derechos y Libertades de los Extranjeros en España y su Integración Social y:

- El TC, declara inconstitucional y nula la inclusión del término "residentes" en los arts. 9.3( derecho a la educación) y 22.2 (asistencia jurídica gratuita) de la Ley Orgánica 4/2000, de 11 de enero, en la redacción dada por la Ley Orgánica 8/2000, de 22 de diciembre ${ }^{12}$

10 Cassese, A.- Los derechos humanos en el Mundo contemporáneo, Barcelona, Ariel, 1991, pág. 8.

11 La discrepancia se centra esencialmente en la construcción doctrinal contenida en los fundamentos jurídicos 3 y 4 , que constituyen la base de sustentación de lo que después a lo largo de ulteriores fundamentos, razonan la inconstitucionalidad de los preceptos, al considerar que si en nuestra Constitución se establece una distinción inicial entre españoles y extranjeros y en nuestro ordenamiento infraconstitucional se establece para las situaciones de estancia ilegal de los ciudadanos extranjeros la medida de su expulsión, el que nuestro ordenamiento legal de ciertos derechos fundamentales de los extranjeros (en este caso los de reunión, asociación y sindicación) se imponga como condición del disfrute y ejercicio por aquéllos la de su estancia o residencia legal en España, resulta de pura coherencia sistemática; empero, resulta contrario a ella la simultaneidad de la garantía de los derechos de que aquí se trata sin exigencia de la referida condición y la previsión de su expulsión por no cumplirla. El art. $13 \mathrm{CE}$, clave en este caso de toda la Sentencia, tal precepto supone una diferenciación de partida de la posición constitucional de los españoles y de los extranjeros.

12 Esta declaración se hace en la STC 236/2007, de 7 de noviembre. En el resto de sentencias, como indica la Sentencia de referencia: La referida declaración de inconstitucionalidad y nulidad (...), determina la pérdida sobrevenida del objeto de esta concreta impugnación, ya que "siendo el efecto inmediato de la anulación de cualquier norma su expulsión del ordenamiento ju- 
- Declara la inconstitucionalidad y nulidad del inciso "cuando estén autorizados a trabajar" del art. 11.2 (derecho a la huelga) de la Ley Orgánica 4/2000, de 11 de enero, en la redacción dada por la Ley Orgánica 8/2000, de 22 de diciembre (STC 258/2007, de 19 de diciembre)

- Declara la inconstitucionalidad, de los arts. 7.1 (derecho de reunión), 8 (derecho de asociación) y 11.1 (exclusivamente respecto al derecho a sindicarse libremente) de la Ley Orgánica 4/2000, de 11 de enero, en la redacción dada por la Ley Orgánica 8/2000, de 22 de diciembre, pero no su nulidad, y

- Desestima los recursos en todo lo demás.

Llama la atención de las sentencias, que el TC declare la inconstitucionalidad, pero no la nulidad, de los artículos 7.1, 8, y 11.1, considerando que no siempre es necesaria la vinculación entre la inconstitucionalidad y la nulidad: "así ocurre cuando "la razón de la inconstitucionalidad del precepto reside, no en determinación textual alguna de éste, sino en su omisión", máxime si tenemos en consideración que en lo que toca a los efectos de las sentencias de inconstitucionalidad, de acuerdo con lo dispuesto en la Ley Orgánica de este Tribunal (art. 39. 1), las disposiciones consideradas inconstitucionales han de ser declaradas nulas, declaración que tiene efectos generales a partir de su publicación en el "Boletín Oficial del Estado" (art. 38.1 LOTC) y que en cuanto comporta la inmediata y definitiva expulsión del ordenamiento de los preceptos afectados (STC 19/1987) impide la aplicación de los mismos desde el momento antes indicado, pues la Ley Orgánica no faculta al TC, a diferencia de lo que en algún otro sistema ocurre, para aplazar o diferir el momento de efectividad de la nulidad.

El TC ya tuvo oportunidad de pronunciarse en el mismo sentido, en las SSTC 45/1989, de 20 de febrero, FJ 11; 222/1992, de 11 de diciembre, FJ 7; 96/1996, de 30 de mayo, FJ 22; y 235/1999, de 20 de diciembre, FJ 13; $138 / 2005$, de 26 de mayo, FJ 6.

En la primera de las sentencia mencionadas, el TC manifestó:

Ni esa vinculación entre inconstitucionalidad y nulidad es, sin embargo, siempre necesaria, ni los efectos de la nulidad en lo que toca al pasado vienen definidos por la Ley, que deja a este Tribunal la tarea de precisar su alcance en cada caso, dado que la categoría de la nulidad no tiene el mismo contenido en los distintos sectores del ordenamiento.

rídico de una vez por todas y para siempre, medida irreversible por su propia naturaleza, la pretensión que se ejercita aquí y ahora resulta ya redundante y vacía de contenido, sin finalidad práctica alguna. En definitiva, una vez que nuestras Sentencias dejan si efecto uno o varios preceptos legales, cualquier otro proceso paralelo o posterior queda desprovisto automáticamente de su propio objeto. Una disposición sólo puede extinguirse una sola vez, por definición ... Tal desaparición sobrevenida del elemento objetivo del proceso impide cualquier consideración sobre lo que en el lenguaje forense ha dado en llamarse el fondo del asunto" (STC 166/1994, de 26 de mayo, FJ 2; ATC 267/2002, de 10 de diciembre, FJ 2). 
La conexión entre inconstitucionalidad y nulidad quiebra, entre otros casos, en aquellos en los que la razón de la inconstitucionalidad del precepto reside, no en determinación textual alguna de éste, sino en su omisión.

Le cumple, pues, al legislador, a partir de esta Sentencia, llevar a cabo las modificaciones o adaptaciones pertinentes en el régimen legal (...), sirviéndose para ello de su propia libertad de configuración normativa que, como hemos venido señalando, no puede ser ni desconocida ni sustituida por este Tribunal Constitucional, al que en un proceso como el que ahora concluye sólo le corresponde apreciar la conformidad o disconformidad con la Constitución de los preceptos enjuiciados (art. 27.1 de su Ley Orgánica), cuya ilegitimidad constitucional, sea cual sea la fórmula utilizada (nulidad o simple inconstitucionalidad) hace jurídicamente imposible su aplicación ....

En el presente caso, como indica el TC: “(...) no procede declarar la nulidad de los artículos de la Ley 8/2000 que garantizan los derechos de reunión, asociación y sindicación a los extranjeros que hayan obtenido autorización de estancia o residencia en España porque ello produciría un vacío legal que no sería conforme a la Constitución, pues conduciría a la denegación de tales derechos a todos los extranjeros en España, con independencia de su situación. Tampoco procede declarar la nulidad solo del inciso "y que podrán ejercer cuando obtengan autorización de estancia o residencia en España", que figura en cada uno de aquellos artículos, puesto que ello entrañaría una clara alteración de la voluntad del legislador ya que de este modo se equipararía plenamente a todos los extranjeros, con independencia de su situación administrativa, en el ejercicio de los señalados derechos. Como hemos razonado anteriormente, no corresponde a este Tribunal decidir una determinada opción en materia de extranjería, ya que su pronunciamiento debe limitarse, en todo caso, a declarar si tiene o no cabida en nuestra Constitución aquélla que se somete a su enjuiciamiento. De ahí que la inconstitucionalidad apreciada exija que sea el legislador, dentro de la libertad de configuración normativa (STC 96/1996), derivada de su posición constitucional y, en última instancia, de su específica libertad democrática (STC 55/1996), el que establezca dentro de un plazo de tiempo razonable las condiciones de ejercicio de los derechos de reunión, asociación y sindicación por parte de los extranjeros que carecen de la correspondiente autorización de estancia o residencia en España. Y ello sin perjuicio del eventual control de constitucionalidad de aquellas condiciones, que corresponde a este Tribunal Constitucional.

Distinto es el alcance del fallo en relación con los preceptos de la Ley 8/2000 relativos al derecho a la educación de naturaleza no obligatoria y al derecho a la asistencia jurídica gratuita de los extranjeros, cuya inconstitucionalidad conlleva la nulidad del inciso "residentes", que figura en cada uno de ellos, pues tales derechos se reconocen constitucionalmente por igual a todos los extranjeros, independientemente de su situación administrativa." (STC 236/2007, de 7 de noviembre). 
Aunque doctrinalmente se ha afirmado ${ }^{13}$ que "las sentencias de mera inconstitucionalidad" son dictadas por el TC cuando sabe que no existe solución al problema plantado ni dictando una sentencia interpretativa, ni anulando el precepto, sino que la solución pasa por una actuación positiva ejercida sobre la norma, llamando al legislador a actuar en base a sus propios criterios, a lo que nosotros añadiríamos también las opciones constitucionalmente aceptadas, la solución ofrecida no nos parece la más adecuada. Parece como si el TC hubiera inventado resoluciones que despliegan efectos no previstos constitucional y legalmente ${ }^{14}$. En efecto, el contenido del art. 39.1 LOTC establece claramente la correspondencia entre inconstitucionalidad y nulidad, conclusión a la que podemos llegar interpretando el art. 40.1 LOTC, y, por supuesto del contenido del art. 164.2 CE. Aunque el propio Tribunal Constitucional ha establecido su capacidad para establecer el alcance de los efectos de la nulidad, dado que la categoría de la nulidad no tiene el mismo contenido en los distintos sectores del ordenamiento (STC 45/1989), entendemos que el principal efecto buscado por el constituyente al incorporar el control de constitucionalidad, consiste en que la declaración de inconstitucionalidad de un precepto, o de parte del mismo, implique su nulidad y, por consiguiente, su expulsión del ordenamiento, en defensa de la propia Constitución.

Si bien el TC, ha puesto de manifiesto la constitucionalidad de una posible modulación, o restricción del ejercicio de determinados derechos a los extranjeros cuando no tengan su situación administrativa regularizada, al ser una opción constitucional del legislador que no se opone a los preceptos constitucionales, lo que no comprendemos es la consideración del TC de que la declaración de nulidad de los artículos legislativos que regulan los derechos de reunión y manifestación; asociación y la libertad de sindicación, produjera un vacío legal que llevara a la negación de estos derechos a todos los extranjeros, con independencia de cual fuera su situación administrativa, puesto que no podemos olvidar que existen derechos y libertades reconocidos constitucionalmente que son directamente aplicables, que no exigen desarrollo legislativo o convencional para que su titularidad y ejercicio sean efectivos, por lo que en ningún caso, un posterior desarrollo legislativo puede atentar contra la forma en que han sido reconocidos constitucionalmente - la propia Constitución, como ha indicado el TC, lejos de ser un mero catálogo...es la Norma Suprema, y esta supremacía determina su efecto y aplicabilidad inmediata-. Respecto de cuales sean estos derechos y libertades, aun cuando la doctrina no es unánime, consideramos que, como mínimo, y en la forma en que lo hace, los derechos fundamentales y las libertades públicas reconocidas en a Sección Primera del Capítulo II del Título I son de aplicación directa, y el po-

13 Garrorena Morales, A.- "Comentario al artículo 164 CE. Condiciones y efectos de las sentencias del TC", en Alzaga Villamil, O (dir).Comentarios a la Constitución Española de 1978, Edersa-Cortes Generales, Tomo XII, 1999, págs 369-370.

14 Rodríguez-Patrón, P. - La "autonomía procesal" del Tribunal Constitucional, Madrid, Thomson-Cívitas, 2003, págs. 68 y ss. 
sible desarrollo legislativo de los mismos debe de partir del contenido constitucionalmente declarado.

Cuando el artículo 53.1 CE establece que los derechos y libertades reconocidos en el Capítulo Segundo del Título I vinculan a todos los poderes públicos, y que sólo por ley, que en todo caso deberá respetar su contenido esencial, podrá regularse el ejercicio de tales derechos y libertades, está reconociendo una vinculación directa e inmediata para los poderes públicos a estos derechos y libertades, toda vez que está reconociendo el principio de aplicación directa de los mismos. Los derechos afectados por esta vinculación y por la cláusula del contenido esencial son plenamente eficaces y aplicables aunque no hubieran sido desarrollados por ley. El desarrollo legislativo a que hace referencia la Constitución es una facultad del legislador, pero no un requisito para la eficacia de estos derechos y libertades fundamentales.

Si el TC vincula los derechos de reunión y manifestación, asociación y la libertad de sindicación a la dignidad del ser humano, y los preceptos constitucionales que los reconocen lo hacen a todas las personas, su contenido constitucionalmente declarado extiende su ejercicio a todos, incluyendo a los extranjeros, con independencia de cual sea su situación administrativa. El TC crea una ficción de difícil encaje. Reconoce la titularidad de estos derechos a los extranjeros, pero no declara la nulidad de las prescripciones "y que podrán ejercer cuando obtengan autorización de estancia o residencia en España", prescripciones que, pese a ser inconstitucionales, no son expulsadas del ordenamiento jurídico y, por lo tanto, siguen siendo aplicables. Lo que suceda en aplicación de estos preceptos por los jueces cuando sea recurrida la posible prohibición de ejercicio por parte inmigrantes no regularizados, irá clarificando la situación jurídica creada, teniendo en consideración que los órganos judiciales tendrán que extraer las consecuencias derivadas de la declaración de inconstitucionalidad. Y ello, porque el legislador no está sometido a plazo alguno para la adopción legal de una política migratoria determinada como le reconoce el TC, de manera que, hasta que la correspondiente regulación legislativa se produzca, se pueden seguir aplicando preceptos legales que han sido declarados inconstitucionales por el Máximo intérprete constitucional.

ABSTRACT: The Spanish Constitutional Court has come to conclusions regarding the no constitutional appeal promoted against Organic Law 4/2000 related to Rights and Liberties for foreiners in Spain and their social integrationin its version given by Organic Law 8/2000. In their resolution, the Spanish Constitutional Court has not only fixed the bases of a new status in rights and liberties for foreiners but also has defined the faculties from Court and Law/Justice. 